\title{
The electoral photograph reloaded: a social semiotic approach
}

Francisco Osvanilson Dourado Veloso

The Hong Kong Polytechnic University, Hong Kong, China

\begin{abstract}
While studies on the role of social media in political campaigns are growing, we still need to understand how well established communicative resources such as political photographs have been adapted in face of the digital transformation. Departing from Barthes (1972) discussion on electoral photographs, this paper discusses the production of Interactive meanings in photographs uploaded by the three main contenders in the Presidential Election 2014 in Brazil. The results show an expansion both in the functions and semiotic strategies adopted to establish a relationship with viewers through electoral photographs.
\end{abstract}

Key-words: political photograph; social semiotics; interactive meanings.

\section{Introduction}

Discourse is a constitutive element of politics as a social practice. In electoral campaigns, more specifically, language and other semiotic resources are deployed in the process of construing a candidate's identity and catering for voters' support. Public speeches at events, rallies and propaganda material such as videos and photographs are instrumental in order to establish a relationship with voters and to build one's own legitimacy by asserting their own qualities - although they can also do it by de-authorizing and delegitimizing their closer competitors (MERRITT, 1984; GARRAMONE et al, 1990). Electoral propaganda seeks to affect the collective imaginary, framing candidates in particular ways, presenting them as capable of offering solutions to problems they strategically bring to the limelight.

Elections are, therefore, a process of mass persuasion where public discourse tools are put to work towards the ultimate goal: guaranteeing a seat as representative at specific legislative positions as established in the political configuration of a modern republic. This concern on discourse and persuasion is not recent and dates back to the ancient Greeks. Aristotle, for instance, elaborated a comprehensive discussion on the use of rhetoric, that is, language use in context, as the art of persuading audiences (ZAREFSKY, 2009). 
Mass persuasion, in contemporary society, however, has assumed different contours, as we have progressed technologically to incorporate meaning-making resources other than language and paralinguistic features such as prosody, voice pitch and proxemics. Among these new semiotic resources, the photograph has emerged as an object of fascination from the start, perhaps because ultimately it is a new form of pictorial representation that feeds from our long history with images, from drawings on caves to the complex Egyptian hieroglyphs, for instance.

Francisco

Osvanilson Dourado Veloso

Digital transformation and the development of social media have transformed the way we produce and consume photographs. Mass persuasion, as a key element in politics and especially during elections has slowly been affected as new ways of communication emerge. We have evolved from an oral society, to pictorial, and then written, and the current digital transformation is slowly bringing us back to a society where the ubiquity of pictures is transforming the way we communicate - and politics is not excluded from this process. The most iconic example at this point might be Barack Obama's Presidential campaign in 2008, when his campaign was able to mobilize around 5 million volunteers through their official website and social media such as Tweeter and Facebook, among others (COGBURN; ESPINOZA-VASQUEZ, 2011; BIMBER, 2014). The production and distribution of images have given unprecedented access to the campaign routine of candidates and opened new ways of establishing a relationship with the viewers and, more specifically, voters.

In this context, this paper sets out to investigate the uses of political photographs by the three main runners in the 2010 Presidential election in Brazil. The data is comprised of photos collected from the official Facebook pages of the candidates Dilma Rousseff, Aécio Neves and Marina Silva. The inclusion of these three candidates is based on polls on voting intention that indicated they were three front runners and the difference between the third and fourth candidates in the polls was far too large, creating a political scenario where two of out the three candidates would challenge each other in a run-off.

The data annotation, based on Kress and van Leeuwen's (2006) categories of interpersonal metafunction for visual grammar, focuses on the investigation of interactive meanings data to understand how candidates make use of visual resources available in the photograph to appeal to voters.

In the following section, I contextualize the use of the electoral photograph in Brazil in elections, present the data and analysis results, followed by the discussion and conclusion. 


\section{From paper to digital: the transformation of the elec- toral photograph.}

For the most part of the last century, the political photograph became an important tool to build a candidate's identity. Perhaps for this reason, Roland Barthes stated they have "a power to convert which must be analysed" (1972, p. 98). The political photograph has a certain appeal as it attempts to establish an interpersonal relationship with the viewer. According to the author, the photograph of a candidate goes beyond the program they have to offer, but implies "a physical climate, a set of daily choices expressed in a morphology, a way of dressing, a posture" (BARTHES, 1972, p. 98), that is, it attempts to create some sort of intimacy with the viewer. However, Barthes warns us the types or styles incorporated in the electoral photograph are not rich in variety. The electoral photograph reloaded: a social semiotic approach They would be limited to construe their social status or respectability, from a Christian candidate in suit and tie, for instance, to more left-wing candidates who, trying to echo the desires of a younger generation, might present themselves in more casual outfits. The second type to be construed in the electoral photograph is the intellectual that Barthes describes as a combination of "thought and will, reflection and action" and finally the "good-looking chap" (1972, p. 99), whose physical attributes and healthy looks are offered as credentials or perhaps even evidence of their capacity to perform the functions they aspire to.

We should note however that Barthes is writing about the political photograph around the 1960 s of the last century. In their material form, photographs circulated only in their print forms. Barthes was talking about a multimodal text designed to circulate on paper, therefore requiring a specific - and limited - process of production. However, as we move into a digital world, the uses of political photographs have been transformed through the use of social media, requiring us to return to them, because they will carry a power to convert but also to understand what transformations the political photograph has undergone, especially in terms of social functions and types.

In Brazil, political photographs have a long history and tradition in their print version. One of the forms of circulation of electoral photographs have been through small leaflets, usually varying in size, as small as a credit card or as large as a passport, in their total dimensions, and appearing in both color and black-and-white versions. The piece of paper in its reduced dimensions works as a canvas, or a hyperframe, in its 
materiality, where semiotic elements, from a candidate's photograph to relevant information conveyed through language, such as name, political affiliation, and a tag-line, are spatially organized. The placement of a candidate's photograph determines the arrangement of all the semiotic elements that will be combined to compose the text as a whole. In this sense, they might resemble 'by-picture' page layout deployed in comicbooks (cf. BATEMAN et al, 2016), where a pictorial element, such as a human figure or object is placed on the page and determines the tessella-

Francisco

Osvanilson Dourado Veloso tion, that is, the placement of all the subsequent elements necessary to compose the text as a whole, in their multimodal configuration.

As for their social function, these small leaflets have always seemed to be to first advertise a candidacy to the public, but also to connect their face, perhaps familiar, to a voting number in the first place, and reveal their affiliation, and to inform of their intentions through a short tag line, all combined to establish a candidate's ethos.

Still used today, the print material has worked as a prototype to the use of political photographs in social media, which seems quite natural insofar as many other genres, such as newspapers and magazines, as they have gone digital, seem to experience a trial period, first importing the paper version into digital and subsequently exploring and - perhaps - realizing the full potential of the digital technology, that affects the processes of production and circulation. Free of the materiality and printing costs involved in the material production, electoral photographs have changed in their semiotic potential, as they can be uploaded instantly or edited to meet different objectives, expanding the meanings they might convey.

\section{Data}

As suggested elsewhere (cf. BATEMAN, 2008; VELOSO, 2014), studies in social semiotics and multimodality require empirical evidence that will support any claims. Therefore, in order to verify how candidates make use of photographs as a resource to establish a relationship with viewers, 470 photographs were collected from the official Facebook campaign album of the candidates Dilma Roussef, Aécio Neves and Marina Silva, the front runners of the Presidential Election 2014 in Brazil. The data collection included every photo uploaded in the period between 26 September to 5 October 2014, that is, the last 10 days of campaign, including the election day, 5 October. 
Figure 1 displays the total number of photographs and their distribution among the three candidates. In the period under investigation, Dilma Rousseffs page presents the highest number of uploads, followed by Marina Silva's album, who displays similar number of photo uploads as Neves. While Neves' Facebook page shows a more consistent uploading pattern in relation to other candidates, with an average of 12.4 pictures a day, Silva shows an increment on posts on 29 September and then reduces uploads again, with a total average of 12.9 pictures a day, which is still very close to Neves' campaign upload pattern. Rousseff, however, within the period under investigation, shows a very different pattern when compared with the other two candidates. While Rousseff shows a descending curve between 26 through 28 September, the following two days register an inversion that maintains an ascending curve, except for October 2 , a day of The electoral photograph reloaded: $a$ social semiotic approach lower upload activity that is retaken on 3 October and continues in a rising curve that reaches its peak on the election day. Silva and Neves, on the other hand, reduced postage of pictures as the election day approached.

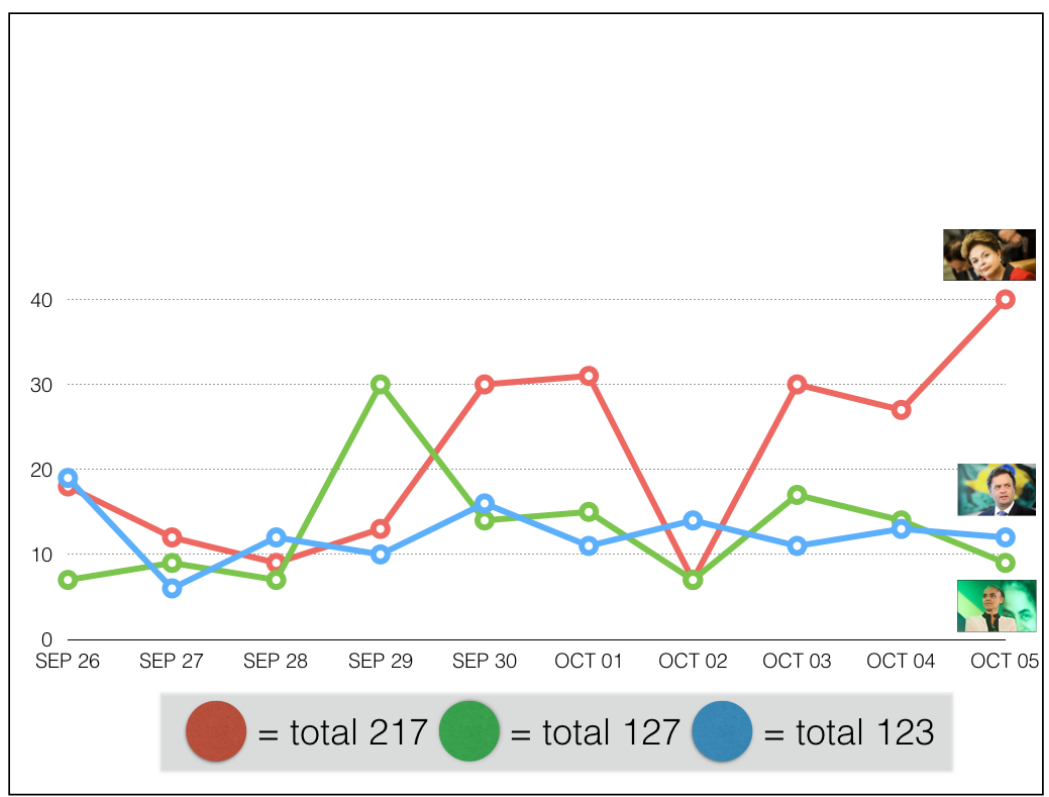

Figure 1: Absolute comparison: distribution of the total number of photos uploaded to candidates' Facebook album between 26 September and \% October 2014.

The photographs from the three candidates were manually assorted and separated into categories based on function. This categories were labelled based on discourse semantics, that is, considering their 
macrostructures, observing topics and themes (cf. van DIJK, 1985; van DIJK, 1995). As it expected from semantic classifications, some posts were relatively straightforward for classification, such as Photographs, corresponding to posts where there is only a picture of the candidate and no slogans or political party number (used for voting) or Proposals. An interesting case is constituted by the category of Countdown, in which both Neves and Silva had well-known public figures such as actors and singers illustrating the post, creating an overlap with Sup-

Francisco

Osvanilson Dourado Veloso port. In any of the cases where it occurred, posts were classified considering the most prominent function. An important difference is that a photo album is no longer used solely to distribute studio photographs. Table 1 shows how photographs are used by the candidates to perform different functions, and these portraits are more spontaneous, showing them in action and participating in social interactions that expand the semiotic potential of their own image as candidates.

\begin{tabular}{|l|l|l|l|}
\hline & Rousseff & Silva & Neves \\
\hline Photographs & 63 & 13 & 50 \\
\hline Proposals & 9 & 10 & 3 \\
\hline Achievements & 16 & 0 & 1 \\
\hline Positioning & 7 & 20 & 8 \\
\hline Photo + Slogan & 2 & 1 & 2 \\
\hline Call for action & 10 & 21 & 2 \\
\hline Slogan & 2 & 0 & 0 \\
\hline The other & 17 & 21 & 12 \\
\hline Support & 54 & 22 & 10 \\
\hline Countdown & 12 & 15 & 10 \\
\hline Poll results & 13 & 0 & 6 \\
\hline Agenda & 12 & 4 & 19 \\
\hline TOTAL & 217 & 127 & 123 \\
\hline
\end{tabular}

Table 1: Functions performed by the campaign material uploaded onto Facebook album of each candidate

After classifying the data in terms of functions, the data reveals that electoral photographs have expanded their semiotic potential and serve more than building a candidate's identity, but become an important communicative asset between represented participants and their target readers, that is, voters. Photographs have become a supporting medium to accomplish a range of purposes, therefore expanding the semiotic potential of what was initially a photo album. Not all of them in fact carry a candidate's photograph, but might use photographs of 
places and other people, cartoon-like illustrations, graphs and language in varying ways to communicate with viewers/voters. In Proposals, for instance, the audience is presented with bullet points that summarize the main ideas of a candidate regarding specific topics, for instance, or to use photos of construction sites in a complementary role with language to present Achievements of former administrative roles each candidate has occupied. These album posts vary in their multimodal configuration, insofar as some of them are prototypically presentation slides and therefore they are not relevant to what is pursued in here, which is to understand how interactive meanings are construed through the candidates' electoral photographs. For this reason, the data has been grouped into two categories, as presented in Table 2 .

The data in the first grouping, photographic posts, displays a The electoral photograph reloaded: $a$ social semiotic approach candidate's image that might be combined with language. Photographic posts are semiotic artefacts that rely on pictorial resources, exploring a candidate's physical traits, making use of angle and gaze, for instance, to communicate with the audience. Although language is deployed in certain types, a photograph is used as a hyperframe and therefore plays an important role in organizing the message. The slide-like group includes any other post that deploys other semiotic resources to create meanings and therefore affect purpose. Under these categories, posts do not carry a candidate's picture. These posts carry varying lengths of language, for instance, and in fact their function seems to be much more ideational, that is, they aim more at construing experience and knowledge by providing reasons or justifications to support the claim that candidate $\mathrm{X}$ is better than $\mathrm{Y}$ or $\mathrm{Z}$, which works as presupposition in a political campaign, and can be conveyed implicitly or explicitly.

\begin{tabular}{|l|l|l|l|}
\hline & Rousseff & Silva & Neves \\
\hline Photographic posts & 105 & 67 & 68 \\
\hline Slide-like posts & 112 & 60 & 55 \\
\hline
\end{tabular}

Table 2: Total number of posts containing photographs of candidates in contrast with slide-like posts

As shown previously, there is a perceptible overall imbalance in the number of posts among the three candidates, that is reflected in Table 2 as well. Considering data and function distribution, this study will focus on Photographs, as displayed in Table 1, to analyse them follo- 
wing Kress and van Leeuwen's (2006) Interactive Meanings. The total number of samples annotated for each candidate is therefore 13, using Marina Silva's album posts as the baseline - Silva's campaign uploaded 13 photos carrying solely her photograph. Therefore a total of 39 samples are annotated in order to explore interpersonal meanings conveyed through electoral photographs.

\section{Interactive meanings: analysis and results}

Francisco

Osvanilson Dourado Veloso

When proposing a grammar for visual analysis, Kress and van Leeuwen (2006) have departed from Halliday's notion of language as social-semiotics (1978), that is, meanings are construed in a social environment with certain purposes or functions, namely ideational (the construction of knowledge and experience), interpersonal (how we establish relationship through language) and textual metafunction (how we organize these meanings in language).

Based on these three metafunctions, Kress and van Leeuwen argue that images as semiotic artefacts also perform these functions and propose a specific taxonomy for annotating and analysing images, instead of directly importing the language categories.

While language is treated, from an interpersonal perspective, as a resource for establishing and maintaining relationship between participants, visual communication in photographs, for instance, poses a different challenge because they ensue two different dimensions. First there is the relationship between participants in a photograph, for instance, which Kress and van Leeuwen categorize as Narrative and Conceptual meanings. The second dimension of the process of communication is between represented participants in photographs and viewers, or readers, that is, how do the participants depicted in a photograph are to be interpreted and what kind of relation might be established with viewers. This relationship between depicted participants and viewers is named as Interactive meanings, that refers to "the interaction between the producer and the viewer of the image" (KRESS; van LEEUWEN, 2006, p. 114)

Interactive meanings in images, or more specifically in photographs as the objective of concern here, might create meanings through contact, social distance and attitude. In terms of contact, participants in a photograph will use gaze to establish a closer or more distant relationship with the viewer; social distance makes use of shot distance to create more intimate or impersonal relationship with the viewer, whi- 
le attitude considers the perspective or angle selection of represented participants to position viewers as more or less involved with/detached from the represented participants.

The analysis of interactive meanings first focuses on contact, which is divided between offer and demand. The first category refers to photos where represented participants do not look at the camera and therefore do not set the gaze on the viewer's direction. These are photos where represented participants, avoiding eye contact with the viewer, become an object of contemplation. This is perhaps the category that best fits Barthes' description of a candidate's appeal in an electoral photograph. Demand, on the other hand, refers to images where represented participants engage with viewers through gazing: looking at the camera lenses creates the illusion that they are looking at the viewer. Of course there might be discordance in those interpretations, because such categories are culturally dependent. Any interpretation of this nature are contingent on how specific cultures treat eye-to-eye contact, as it might involve issues of hierarchy, power, and gender to understand how looking at someone else's eye directly, or not, might mean. In some cultures it might be offensive exactly because it searches for an intimacy that might not be expected in public spaces, or less acquainted people. However, in the particular context of the Brazilian culture, looking someone in the eyes is interpreted as desirable when attempting to build a relationship of trust. Avoiding eye contact is exactly the opposite, a sign of mistrust and lack of confidence.

The analysis of contact for each of the three candidates reveals that offer is the preferred form of representation, although Neves is the candidate that makes more use of this type of visual composition when compared with the other two candidates - he seems to be construed as an object of contemplation (Figure 2). Rousseff, however, makes use of Demand, that is, looking the viewer in the eye, twice as much as Silva and almost three times more than Neves. While classifying the photographs in relation to gazing contact allow us to quantify, interpreting the data is not exact science, but demonstrates a disposition from Rousseff to invite the viewer in, which matches with her approach in public appearances, when she adopts a more direct and confrontational position in debates, interviews and other public appearances. 


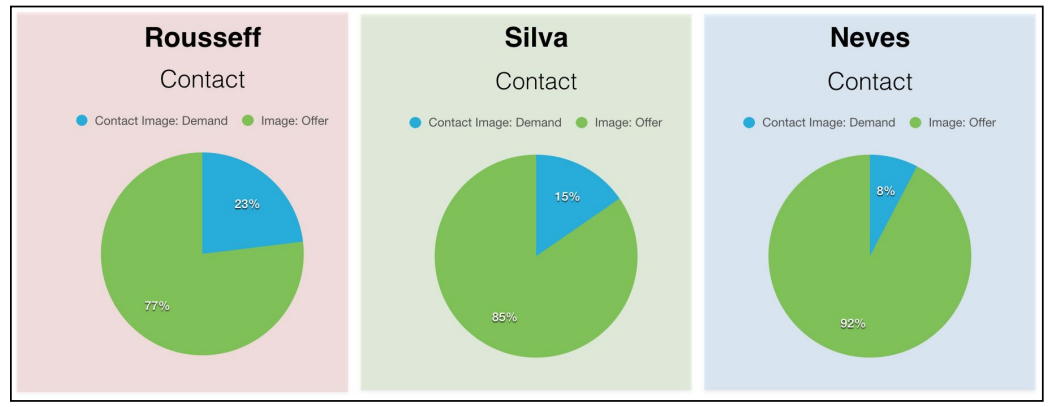

Francisco

Osvanilson

Dourado Veloso

Figure 2: Eye contact of candidates

The second category analysed in the selected data was social distance, which is divided in personal, social and impersonal meanings, which are identified based on close, medium and long shots, respectively. Close shots are those that display represented participants at shoulder and head distance; medium shots show participants from the waist up and long shots display the whole body. Figure 3 summarises the analysis results for each of the three candidates. In this category, Rousseff is the one candidate who uses the most close shots, with $62 \%$ percent of her photographs being of this type, while Neves stands in second place with $23 \%$ and Silva with only $15 \%$ of her photographs as close shots.

Both Silva and Neves campaigns make more use of medium shots - and therefore establishing more of a social relationship with the viewer. The three candidates show a lower occurrence of long shots and therefore avoid establishing an impersonal relationship with viewers, which is in fact counter-productive when the main purpose of these photographs is to gather more electoral support.

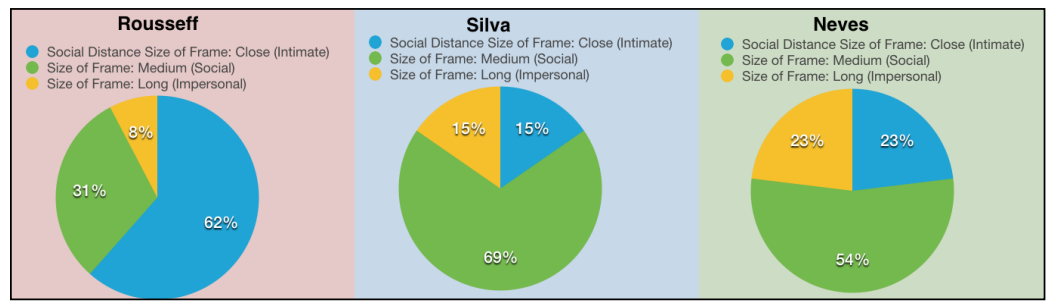

Figure 3: Social distance of candidates

The third and final classification for interactive meanings is related to attitude, or how participants are displayed in terms of perspective or angle in relation to the viewer. Attitude is divided into two 
main entries accordingly with Kress and van Leeuwen (2006, p. 149), Subjectivity and Objectivity. Because of the aim in this article is to examine the electoral photograph appeals to the reader, the analysis focuses only on the categories of Involvement and Detachment, which are more relevant in this case. Vertical angle is related to issues of power and requires a different theoretical and analytical approach for data analysis and discussion and therefore are not an object of discussion in here. Figure 4 shows how each of the candidates' campaign explore the semiotic potential of angle in the electoral photographs.

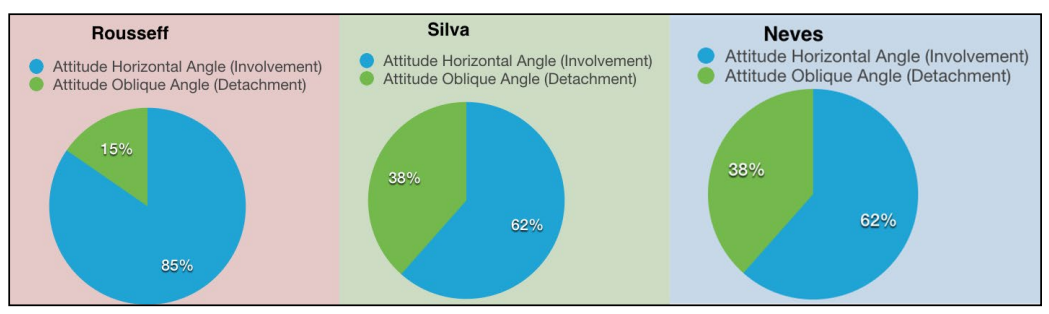

The electoral photograph reloaded: a social semiotic approach

Figure 4: Attitude of candidates

Rousseff's analysis results demonstrates that her uploaded photographs are the ones with the highest rate of horizontal angle, that is, a frontal angle that creates a message of inclusion or, to use Kress and van Leeuwen's terms, it says that "what you see here part of our world, something we are involved with" (2006, p. 136), which is extremely important if we consider the nature of an electoral campaign, which consists of bringing voters in to understand that what is at stake are of relevance to their lives. The results for Silva and Neves are the same, with the two photo albums sharing more photos with horizontal than oblique angles, validating the point raised above that, for a campaign, bringing voters to understand that what is under discussion is important to them, not simply to the represented participants, the candidates.

\section{Conclusion}

The main goal of this study is to verify how political candidates explore the semiotic potential of interactive meanings in electoral photographs. One of the starting points of this study is Roland Barthes's essay on the electoral photograph, and how it construes a certain appeal around the imagine of a candidate. According to Barthes, these photographs convey mainly three types of meanings around a candidate, that is, a 
represented participant in electoral photos, namely, the respectable, the intellectual and the good-looking candidates. As technology has had a remarkable impact in the process of production and consumption of advertising material, and social media has altered the way we communicate, which affects also the way campaign material is distributed.

The digital transformation has facilitated production of campaign material and therefore allowed the expansion of the semiotic potential of posters and leaflets, as digital production has reduced

Francisco

Osvanilson Dourado Veloso tribution of photos. In fact, the photograph has become an even more essential part of the quotidian and a preferred media for marketing purposes, such as electoral propaganda.

In this article, a total of 39 samples of electoral photographs from the three front-runners of the 2014 Presidential election in Brazil were analysed to investigate the way electoral photographs explore their semiotic potential. The analysis was carried out by annotating the data based on the interactive meanings as postulated by Kress and van Leeuwen (2006).

The results demonstrate that, in terms of contact, the analysis supports Barthes' claims that electoral photographs do offer themselves for inspection and evaluation but as production is now of easy access, candidates are not just contemplating the horizon as if looking at a brilliant promised future they see ahead of them, as photos are now not limited to studios, but capture candidates activities during the campaign. That is, photos with looks that seem to suggest deep motives are now sharing space with those that convey more actions, that is, doings.

In terms of social distance, the three candidates explore more close shots and avoid long shots, as such they procure to create a personal relationship with viewers. The use of angle or perspective among candidates vary between Rousseff in relation to Silva and Neves, as the former makes more use of horizontal angles that enhance involvement with the viewer, which is combination with the higher use of photos that 'demand' the attention of viewers through direct gazing reinforce the strategy of interacting with viewers.

Overall, if we examine the results and consider the variables at play, it is possible to argue that Rousseff makes more effective use of the semiotic potential of photos - an interpretation that is reinforced by the fact that she is the one who has more photos uploaded to her Facebook photo album. Coincidently, Rousseff is the one candidate who ultimately 
won the election in the run-off but then one cannot claim that her victory lies only on this, because votes are decided not only based on ones' own qualities but also on the lack of certain qualities in other candidates. Quality should be understood here in a broad sense as it includes also the capacity to effectively communicate and establish rapport with voters, which includes understanding necessities and expectations.

As social media increase their role in everyday life, and the world seems more unstable both economically and politically, it is urgent that academics and researches, especially in the humanities, aim at further understanding their role in society, and how they affect electoral processes, as voters are now active agents that transform meanings. Analysing empirical data that demonstrates how these campaign materials are circulated and transformed through posts, for instance, are key to understanding the degree to which they affect electoral results.

Another important result from this discussion is perhaps broader in its scope. As I explore interactive meanings, it should be noted that they are much more related to pathos than logos, if we consider the Aristotelian meanings for these words when explaining rhetoric. As social media, as a business, have become an ubiquitous aspect of social life, it seems that one its corollaries is the rising of the role played by relationships and, most importantly, emotions into public discourse, including in politics. The rise of a candidate such as Donald Trump in the U.S.A. Presidential elections in 2016, with very little to offer in terms of ideas, but who was voted as Republican nominee, indicate that interpersonal meanings have become more important then ideational meanings and understanding how this process takes place at different levels of communication, from language to visual communication is key to shaping educational discourse for future generations.

\section{REFERENCES}

BARTHES, Roland. Mythologies. London: Paladin, 1972.

BATEMAN, John. Multimodality and genre: a foundation for the systematic analysis of multimodal documents. London: Palgrave Macmillan, 2008. 
BATEMAN, John; VELOSO, Francisco; WILDFEUER, Janina; CHEUNG, Felix HiuLaam; GUO, Nancy Songdan. An open multilevel annotation scheme for the visual layout of comics and graphic novels: definitions and design. Digital Scholarship in the Humanities, DOI: DOI: http://dx.doi.org/10.1093/llc/fqw024, 2016.

BIMBER, Bruce. Digital media in the Obama campaigns of 2008 and 2012: adaptation to the personalized political communication en-

Francisco

Osvanilson Dourado Veloso

COGBURN, Derrick L.; ESPINOZA-VASQUEZ, Fatima K. From networked nominee to networked nation: examining the impact of Web 2.0 and social on political participation and civic engagement in the 2008 Obama Campaign. Journal of Political Marketing, v. 10, n. 1-2, p. 189-213, 2011.

GARRAMONE, Gina M.; ATKIN, Charles K.; PINKLETON, Bruce E.; COLE, Richard T. Effects of negative political advertising on the political process. Journals of Broadcasting and Media, v. 34, n. 3, p. 299-311, 1990.

KRESS, Gunther; van LEEUWEN, Theo. Reading images: the grammar of visual design. 2 ed. London: Routledge, 2006.

HALLIDAY, Michael A. K. Language as social semiotic: the social interpretation of language and meaning. London \& Baltimore: Edward Arnold \& University Park Press, 1978.

MERRITT, Sharyne. Negative political advertising: some empirical findings. Journal of Advertising, v. 13, n. 3, p. 27-38, 1984.

Van DIJK, Teun A. Semantic discourse analysis. In: (Ed.). Handbook of discourse analysis, Vol. 2: dimensions of discourse. Academic Press: London, 1985. pp. 103-112.

Van DIJK, Teun A. Discourse semantics and ideology. Discourse \& Society, v. 6, n. 2, p. 243-289, 1995. 
VELOSO, Francisco. O. Dourado. Pesquisa em multimodalidade: Por uma abordagem sociossemiótica. In: GONÇALVES, Adair Vieira; SILVA, Wagner Rodrigues. Visibilizar a Linguística Aplicada: abordagens teóricas e metodológicas. Campinas, SP: Pontes, 2014. pp. 155-180.

ZAREFSKY, David. History of public discourse studies. In: LUNSFORD, Andrea A.; WILSON, Kirt H.; EBERLY, Rosa A. (Eds.). The SAGE handbook of rhetorical studies. Thousand Oaks, California: SAGE Publications Inc., 2009. pp. 433-459.

The electoral photograph reloaded: a social semiotic approach 87 
